\title{
Microorganisms' effect on the wettability of carbonate oil-wet surfaces: implications for MEOR, smart water injection and reservoir souring mitigation strategies
}

\author{
Moein Jahanbani Veshareh ${ }^{1,2}$. Shahab Ayatollahi ${ }^{2}$
}

Received: 3 April 2019 / Accepted: 4 September 2019 / Published online: 12 September 2019

(c) The Author(s) 2019

\begin{abstract}
In upstream oil industry, microorganisms arise some opportunities and challenges. They can increase oil recovery through microbial enhanced oil recovery (MEOR) mechanisms, or they can increase production costs and risks through reservoir souring process due to $\mathrm{H}_{2} \mathrm{~S}$ gas production. MEOR is mostly known by bioproducts such as biosurfactant or processes such as bioclogging or biodegradation. On the other hand, when it comes to treatment of reservoir souring, the only objective is to inhibit reservoir souring. These perceptions are mainly because decision makers are not aware of the effect microorganisms' cell can individually have on the wettability. In this work, we study the individual effect of different microorganisms' cells on the wettability of oil-wet calcite and dolomite surfaces. Moreover, we study the effect of two different biosurfactants (surfactin and rhamnolipid) in two different salinities. We show that hydrophobe microorganisms can change the wettability of calcite and dolomite oil-wet surfaces toward water-wet and neutral-wet states, respectively. In the case of biosurfactant, we illustrate that the ability of a biosurfactant to change the wettability depends on salinity and its hydrophilic-hydrophobic balance (HLB). In distilled water, surfactin (high HLB) can change the wettability to a strongly water-wet state, while rhamnolipid only changes the wettability to a neutral-wet state (low HLB). In the seawater, surfactin is not able to change the wettability, while rhamnolipid changes the wettability to a strongly water-wet state. These results help reservoir managers who deal with fractured carbonate reservoirs to design a more effective MEOR plan and/or reservoir souring treatment strategy.
\end{abstract}

Keywords Microbial enhanced oil recovery $\cdot$ Reservoir souring $\cdot$ Fractured carbonate reservoirs $\cdot$ Wettability alteration $\cdot$ Bacteria cells $\cdot$ Smart water injection

\section{Introduction}

Hydrocarbon reservoirs as a major part of the deep subsurface biosphere host indigenous microorganisms that live under harsh pressure and temperature conditions. After thousands of decades, these diffusion-driven environments have been isolated and stabilized. However, this stability can be

Electronic supplementary material The online version of this article (https://doi.org/10.1007/s13202-019-00775-6) contains supplementary material, which is available to authorized users.

Moein Jahanbani Veshareh

Moein@dtu.dk

1 Danish Hydrocarbon Research and Technology Centre, Technical University of Denmark, Lyngby, Denmark

2 Department of Chemical and Petroleum Engineering, Sharif University of Technology, Tehran, Iran violated during petroleum exploitation through processes such as reservoir souring and microbial enhanced oil recovery (Vigneron et al. 2017).

About 50\% of oil resources have been placed in carbonate reservoirs. Carbonate reservoirs are often fractured with a relatively low matrix permeability, and on top of that, they are in most of the cases neutral-wet or oil-wet. Therefore, water flooding recovery from carbonate reservoirs is generally low (Strand et al. 2006). In order to increase the recovery from these reservoirs, different research works have suggested different methods such as surfactant injection and smart water injection to change the wettability of carbonate surfaces, and stimulate imbibition process (Austad et al. 1998; Strand et al. 2006).

Recently Hajibagheri et al. $(2017,2018)$ and (NajafiMarghmaleki et al. 2018) studied the effect of different biosurfactant-producing bacteria on the wettability of oil-wet carbonate surfaces. Hajibagheri et al. $(2017,2018)$ showed

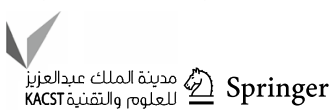


that bacterial solution of Enterobacter cloacae can change wettability of calcite surfaces from a strongly oil-wet state toward a strongly water-wet state. Najafi-Marghmaleki et al. (2018) showed that bacterial solution of an Alcaligenes faecalis strain can change the wettability of an oil-wet carbonate surface toward a neutral-wet condition. Note that the bacterial solution experimented by Hajibagheri et al. (2017, 2018) and Najafi-Marghmaleki et al. (2018) is composed of both bacteria cells and bioproducts. Therefore, following questions are left unanswered:

1. Are microorganisms cell responsible for the wettability alteration?

2. Are the produced biosurfactants responsible for the wettability alteration?

3. What is the effect of microorganisms and their produced biosurfactant on other carbonate surfaces such as dolomite?

If the answer to the first question is yes, it means that in the reservoir souring process, besides side effects there might be also some extent of enhanced oil recovery. Therefore, it introduces a new constraint for reservoir souring mitigation strategies. The answer to the first question is also important for researchers who study the effect of sulfate in smart water injection processes, as sulfate injection can stimulate sulfate reducing bacteria growth. If microorganisms are able to change the wettability, one mechanism of wettability alteration in smart water injection process can be microbial activities.

For MEOR, the positive answer to the first question can make MEOR process applicable where it is not regarded to be applicable. By looking into the work of Hajibagheri et al. (2017, 2018) and Najafi-Marghmaleki et al. (2018), one can see the bacterial solution has a significant concentration of $\mathrm{K}_{2} \mathrm{HPO}_{4}$ and $\mathrm{KH}_{2} \mathrm{PO}_{4}$, as phosphate ions are essential for biosurfactant production. In the real field application, injection of such solution into the reservoir is not possible, as it is not compatible with the carbonate reservoirs brine [with a significant concentration of $\mathrm{Ca}^{2+}$ (Austad 2013)]. It is also may not be possible to find a biosurfactant-producing microorganism that can tolerate the harsh condition of the reservoir. However, this does not mean wettability alteration is not possible, as there might be microorganisms that do not need a significant concentration of $\mathrm{K}_{2} \mathrm{HPO}_{4}$ and $\mathrm{KH}_{2} \mathrm{PO}_{4}$ to grow, and they cannot produce biosurfactant, but they can tolerate the reservoir condition and they can change the wettability.

The second question and third questions are also important. So far, in most of the research works on MEOR (targeting wettability alteration), only biosurfactant production has been considered as the screening criteria for isolation of microorganisms. However, if different biosurfactants influence different carbonate surfaces differently, the rock type should be also considered in the screening procedure.

In this work, we seek to establish some guidelines to predict the effect of microbial associated processes such as seawater injection and MEOR on the wettability of oil-wet carbonate reservoirs. To this end, we reveal the individual effect of bacteria cells and biosurfactants on the wettability of two different oil-wet carbonate surfaces (calcite and dolomite). This is done by evaluating the effect of five different bacteria (isolated from seawater, oil contaminated soil and oil samples) and two different biosurfactants (surfactin and rhamnolipid) on the carbonate surfaces. In assessing biosurfactant effect, we also consider the effect of salinity. We suggest mechanisms through which a bacteria cell or a biosurfactant can change the wettability and reasons why they cannot change the wettability in some cases. At last, in the light of our results, we recommend a new screening constraint for MEOR, a new guideline for decision makers who are facing the challenge of reservoir souring and a new mechanism for sulfate-associated smart water injection.

\section{Materials and methods}

\section{Microorganisms used}

In this work, we used three known strains Bacillus subtilis MJ01, Pseudomonas aeruginosa MJ03 and Acinetobacter calcoaceticus PTCC 1318. Additionally, we used strains that were isolated from a petroleum reservoir oil sample and a seawater sample. In the following, sampling and isolation procedures to obtain these strains are explained.

\section{Sampling}

We used sterile urine sample bottles to collect samples. Cap of bottles was sealed with parafilm, and they were kept at $4{ }^{\circ} \mathrm{C}$. The reservoir oil sample was taken from the production pipeline. Note that the oil sample contained also some emulsified reservoir water. In order to minimize any pollution, the seawater sample was taken from a point about $100 \mathrm{~m}$ away from the beach and about $50 \mathrm{~cm}$ below the seawater.

\section{Isolation}

Figure 1 shows the isolation procedure utilized in this work schematically.

Bacteria isolation from the seawater sample To isolate bacteria present in the seawater sample, we used seawater nutrient broth (SNB) obtained by dissolving 5 grams of peptone, 5 grams of yeast extract and 3 grams of beef extract in a liter of seawater (Atlas 2005). Fifty milliliters of the prepared 


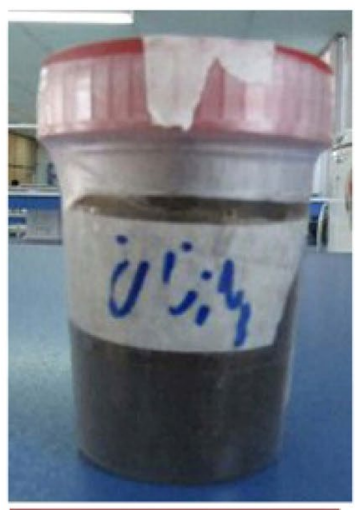

Sampling
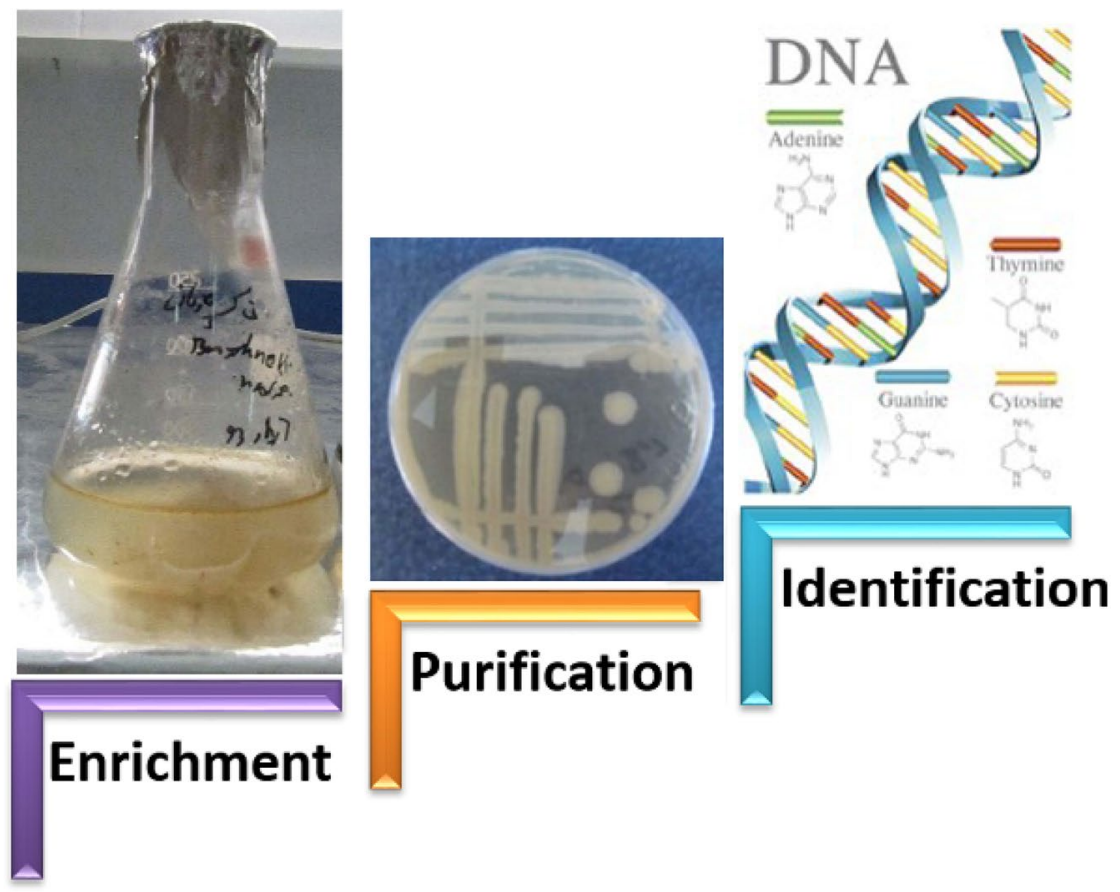

Fig. 1 Schematic representation of the isolation procedure of MJ01 and MJ03

medium after autoclaving was added to a 250-ml Erlenmeyer and then was inoculated with $1 \% \mathrm{~V} / \mathrm{V}$ of the seawater sample. The incubation was done at $30^{\circ} \mathrm{C}, 160 \mathrm{rpm}$ and for 4 days. Afterward, different dilutions (up to $10^{-8}$ ) of the culture were spread on agar plates made by the aforementioned media. After 1-3 days of incubation, to obtain pure cultures, grown colonies were recultivated in fresh agar plates for at least three times.

Bacteria isolation from the reservoir oil sample The procedure of bacteria isolation from the reservoir oil sample has been described in detail in the work of (Veshareh et al. 2019) under the section "Isolation of oil degrading bacteria," where in this work we did the enrichment by using two $\mathrm{ml}$ of the oil sample.

\section{Bacteria identification}

The identification procedure has been described in detail in the work of (Veshareh et al. 2019), under the section "Identification of bacteria."

\section{Growth media used}

\section{Seed culture}

For the seawater strain, we used SNB medium. Fifty milliliters of SNB medium were autoclaved in a 250-ml Erlenmeyer flask and were inoculated with a loop full of the strain, which had been previously cultivated and grown on SNB agar medium. The inoculated Erlenmeyer flask was incubated for $24 \mathrm{~h}$ at $30^{\circ} \mathrm{C}, 160 \mathrm{rpm}$. In the end, the optical density of the culture at $600 \mathrm{~nm}$ was set to 1 , using sterile SNB medium. For other strains, we used a seed culture medium that was prepared following the instructions in the work of Veshareh et al. (2019) under the section "Seed culture preparation."

\section{Biomass production media}

For the strain isolated from the seawater, we used SNB medium. For MJ03 strain, we used mineral salt solution (MSSO) medium reported by (Sarafzadeh et al. 2014) with 
sunflower oil as the sole carbon source. For other strains, we used Luria-Bertani (LB) medium.

\section{Seawater/formation brine compatible growth medium (SBCGM)}

Seawater and most of formation brines that belong to carbonate reservoirs include high quantity of $\mathrm{Ca}^{2+}$ and $\mathrm{Mg}^{2+}$ cations (Austad 2013). Therefore, $\mathrm{H}_{2} \mathrm{PO}_{4}^{-}$and $\mathrm{HPO}_{4}{ }^{2-}$ anions concentration in the growth media considered for microbial enhanced oil recovery should be kept in the solubility limit of $\mathrm{Ca}\left(\mathrm{H}_{2} \mathrm{PO}_{4}\right)_{2}, \mathrm{Mg}\left(\mathrm{H}_{2} \mathrm{PO}_{4}\right)_{2}, \mathrm{CaHPO}_{4}$ and $\mathrm{MgHPO}_{4}$. It is clear that ignoring this constraint may lead to a severe formation damage due to scale formation.

To consider this constraint, we modified the mineral salt solution introduced by (Darvishi et al. 2011) by changing the $\mathrm{KH}_{2} \mathrm{PO}_{4}$ and $\mathrm{K}_{2} \mathrm{HPO}_{4}$ concentrations to be 2 and $0 \mathrm{~g} / \mathrm{l}$, respectively.

\section{Biomass preparation}

Biomass production media after autoclaving were inoculated by seed cultures $(1 \% \mathrm{~V} / \mathrm{V})$, and then, incubation was done at $30{ }^{\circ} \mathrm{C}, 160 \mathrm{rpm}$. Afterward, cells were separated by centrifuging at $9000 \mathrm{rpm}$ for $15 \mathrm{~min}$. In order to ensure the separated biomass is clear of any nutrient and bioproduct such as biosurfactant, cells were washed by distilled water (by suspending cells in distilled water and separating them by centrifugation) for three times.

\section{Biosurfactant preparation}

Surfactin used in this work was separated from MJ01 strain as has been reported by Veshareh et al. (2019) under the section "Purification and partial identification of biosurfactant using FTIR." Rhamnolipid was produced by MJ03 strain, using MSSO medium reported in the work of (Sarafzadeh et al. 2014). The autoclaved media were inoculated with $(1 \% \mathrm{~V} / \mathrm{V})$ of MJ03 seed culture, and then, incubation was done at $30^{\circ} \mathrm{C}, 160 \mathrm{rpm}$ for 2 days. To separate rhamnolipid, firstly, cells were removed from cultures by centrifuging at $9000 \mathrm{rpm}$ for $15 \mathrm{~min}$. Then, cell-free supernatants were acidified using $6 \mathrm{M} \mathrm{HCl}$ to $\mathrm{pH} 2.0$. Afterward, the precipitated rhamnolipid was separated by centrifuging at
$9000 \mathrm{rpm}$ for $20 \mathrm{~min}$. Since (after centrifugation) the separated rhamnolipid was as a layer floating on the supernatant, we used a filter paper (MF-Millipore Mixed Cellulose Ester Membrane Filter) to separate it. Rhamnolipid attached on the filter paper was extracted using ethyl acetate. Lastly, the ethyl acetate was completely evaporated at $45^{\circ} \mathrm{C}$ to obtain a partially pure rhamnolipid as a maple syrup shape liquid.

\section{Bacterial adhesion to hydrocarbon (BATH) test}

To determine the relative hydrophobicity of different strains used in this work, we used BATH test described in the work of (Dorobantu et al. 2004).

\section{Contact angle measurements}

Detail information about contact angle tests including the procedure used to take rock slices, age samples and measure contact angle can be found in the work of Veshareh et al. (2019) under the section "Wettability studies." An asphaltenic crude oil (acid number $=0.58 \mathrm{mg} \mathrm{KOH} / \mathrm{g}$ oil) was used in contact angle measurements. The crude oil composition and its properties are listed in Tables 1 and 2 , respectively. Acid and base numbers were determined based on ASTM D-664 and ASTM D-2289, respectively. Rock slices were taken from two different carbonate outcrops. Based on X-ray diffraction analysis (XRD), one of these outcrops is shown to be composed of mainly calcite, while the other one was interpreted to be mainly dolomite.

Wettability (contact angle) of rock slices was measured in three stages. The first stage was right after preparation of the rock slice $\left(\theta_{i}\right)$. Next stage was after the aging procedure when the wettability of rock slices had changed to an oilwet state $\left(\theta_{o}\right)$. The last stage was after treatment with three categories of solutions $\left(\theta_{f}\right)$, all for a week, and at $30^{\circ} \mathrm{C}$. The temperature of $30^{\circ} \mathrm{C}$ was considered in order to ensure the wettability alterations measured in this work are solely due to the effect of added bioproducts (active/inactive biomass or biosurfactant) not the distilled water or the seawater (Austad et al. 2011; Mahani et al. 2015). Note that the time period of 1 week was chosen because Hajibagheri et al. $(2017,2018)$ observed that the wettability alterations mainly occurs in the first 3-6 h. Therefore, we assumed that the time period of 1 week is long enough for any potential changes to show up.
Table 1 Contact angle measurement results for control cases; at $30^{\circ} \mathrm{C}$ seawater and distilled water have an insignificant effect on the wettability of calcite and dolomite surfaces

\begin{tabular}{llllll}
\hline Fluid type & Mineral type & \multicolumn{2}{l}{ Contact angle $\left(^{\circ}\right)$} & \multirow{2}{*}{$\begin{array}{l}\text { Wettability } \\
\text { alteration }\end{array}$} \\
\cline { 3 - 5 } & & Initial & Aged & Final & \\
\hline Seawater & Calcite & $30.45 \pm 3.7$ & $150.8 \pm 3.8$ & $139.0 \pm 2.5$ & $10 \pm 6$ \\
& Dolomite & $28.9 \pm 0.8$ & $157.9 \pm 4.7$ & $139.7 \pm 3.2$ & $14 \pm 7$ \\
\multirow{2}{*}{ Distilled water } & Calcite & $32.8 \pm 3.5$ & $155.5 \pm 4.1$ & $139.5 \pm 3.6$ & $13 \pm 7$ \\
& Dolomite & $31.9 \pm 1.8$ & $167.3 \pm 2.6$ & $147.6 \pm 2.4$ & $15 \pm 4$ \\
\hline
\end{tabular}


Table 2 Contact angle measurement results for two different biosurfactants: surfactin and rhamnolipid; surfactin can change wettability of calcite and dolomite surfaces only in distilled water, while rhamnolipid is effective also in seawater

\begin{tabular}{|c|c|c|c|c|c|c|}
\hline \multirow[t]{2}{*}{ Biosurfactant } & \multirow[t]{2}{*}{ Base } & \multirow[t]{2}{*}{ Mineral type } & \multicolumn{3}{|c|}{ Contact angle $\left({ }^{\circ}\right)$} & \multirow{2}{*}{$\begin{array}{l}\text { Wettability } \\
\text { alteration }\end{array}$} \\
\hline & & & Initial & Aged & Final & \\
\hline \multirow[t]{4}{*}{ Surfactin } & \multirow[t]{2}{*}{ Seawater } & Calcite & $29.8 \pm 3.1$ & $145.0 \pm 5.8$ & $120.7 \pm 1.5$ & $22 \pm 8$ \\
\hline & & Dolomite & $24.7 \pm 2.3$ & $158.6 \pm 1.5$ & $157.2 \pm 4.6$ & $1 \pm 5$ \\
\hline & \multirow[t]{2}{*}{ Distilled water } & Calcite & $45.1 \pm 3.5$ & $161 \pm 1.4$ & $43.3 \pm 3.7$ & $102 \pm 9$ \\
\hline & & Dolomite & $36.0 \pm 0.7$ & $158.7 \pm 2.2$ & $38.6 \pm 1.5$ & $98 \pm 5$ \\
\hline \multirow[t]{4}{*}{ Rhamnolipid } & \multirow[t]{2}{*}{ Seawater } & Calcite & $26.3 \pm 2.2$ & $158.9 \pm 3.4$ & $40.1 \pm 5.0$ & $90 \pm 1$ \\
\hline & & Dolomite & $33.5 \pm 4.6$ & $162.5 \pm 5.8$ & $35.4 \pm 2.3$ & $100 \pm 14$ \\
\hline & \multirow[t]{2}{*}{ Distilled water } & Calcite & $27.0 \pm 1.9$ & $162.8 \pm 2.9$ & $92.7 \pm 2.5$ & $52 \pm 6$ \\
\hline & & Dolomite & $29.5 \pm 3.4$ & $150.4 \pm 3.6$ & $103.9 \pm 1.1$ & $39 \pm 6$ \\
\hline
\end{tabular}

Najafi-Marghmaleki et al. (2018), in their contact angle measurements, placed rock slices in different solutions including a formation brine and microbial solutions. However, since contact angle depends on the interfacial tension (IFT) of fluids, and biosurfactants reduce IFT, in all of our contact angle tests we placed the rock slices in distilled water so that we ensure the difference in the contact angle results is only due to surface modifications. In order to facilitate interpretation of contact angle data, we used the concept of wettability reversal percent (WRP) introduced by Veshareh et al. (2019).

$\mathrm{WRP}=\frac{\theta_{o}-\theta_{f}}{\theta_{o}-\theta_{i}} \times 100$

Theoretically, WRP can accept values between 0 and 100 . WRP values close to 0 show no wettability modification, while WRP values close to 100 indicate that the surface has regained its initial wettability state. Note that considering uncertainties in contact angle measurements, measured WRP values can be out of this theoretical range. In the following, three categories of treating solution are explained.

\section{Control solutions}

Different solutions in this work were made by either distilled water or seawater. Therefore, we measured the effect of both distilled water and seawater on aged rock slices so that we can differentiate the effect of bacteria and/or biosurfactants on the measured contact angle tests. For seawater, we used Persian Gulf seawater with the total dissolved solid content of $42.145 \mathrm{ppm}$.

\section{Inactive biomass suspensions}

These tests were designed to study the sole effect of bacteria cells on wettability of calcite and dolomite surfaces. In fact, this study was needed to check whether the effect of active microorganisms on wettability is due to their cell surface properties or is due to their biologic activity. To prepare inactive biomass solution, washed biomasses obtained in Sect. 2.3 were suspended in distilled water $(0.5 \mathrm{mg} / \mathrm{l}$ concentration) to make inactive biomass suspensions. Since gram-negative and gram-positive bacteria have different cell surface properties, for these tests we considered a gramnegative bacterium and a gram-positive bacterium.

\section{Active biomass suspensions}

These tests were designed to answer two main questions:

1. In microbial enhanced oil recovery in oil-wet carbonate reservoirs, does only biosurfactant production contributes in oil recovery?

2. Are microorganisms without ability of biosurfactant production able to increase oil recovery?

Indeed, the second question is a reformulated version of the first question. For these tests, as the high temperature and humidity of the autoclave would affect the wettability, we used UV wave to sterilize rock slices. SBCGM without any carbon source was used to keep bacteria active. After the media were cooled down, rock slices were placed and $3 \%$ inoculation from the seed culture was done. Rock slices with active bacteria suspensions were incubated for a week at $30{ }^{\circ} \mathrm{C}$, without any shaking. Note that we removed the carbon source from SBCGM in order to prevent significant growth and bioproduct production to ensure wettability is only influenced by cells biotic or abiotic activity.

\section{Results and discussion}

\section{Isolated microorganisms}

16S rRNA partial sequence revealed that MJ02 and MJ04 strains are Halomonas aquamarina (97\% similarity) and Bacillus subtilis (98\% similarity), respectively. The $16 \mathrm{~S}$ rRNA genes of MJ02 and MJ04 were deposited in the GenBank database with accession numbers MK245973 and MK244694, respectively. 


\section{Hydrophobicity of different strains}

Figure 2 shows the hydrophobicity of different strains used in this work. Strains MJ01, MJ02 and MJ04 were found to be highly hydrophil, while strains MJ03 and PTCC 1318 showed to be partially and highly hydrophobe, respectively.

\section{Contact angle results}

Before discussing the contact angle results, it is worth reminding that all of the treatments in this work were done in $30^{\circ} \mathrm{C}$. Considering that petroleum reservoirs have different temperatures higher than $30^{\circ} \mathrm{C}$, any conclusion we will make from here on needs to be checked before being applied to a specific petroleum reservoir. However, due to the following two reasons we speculate that the same observations will be observed using higher temperatures:

- Bacterial growth can happen in temperatures up to (Stetter and Huber 2000).

- Biosurfactants and biomass are relatively stable in high temperatures (Al-Bahry et al. 2013).

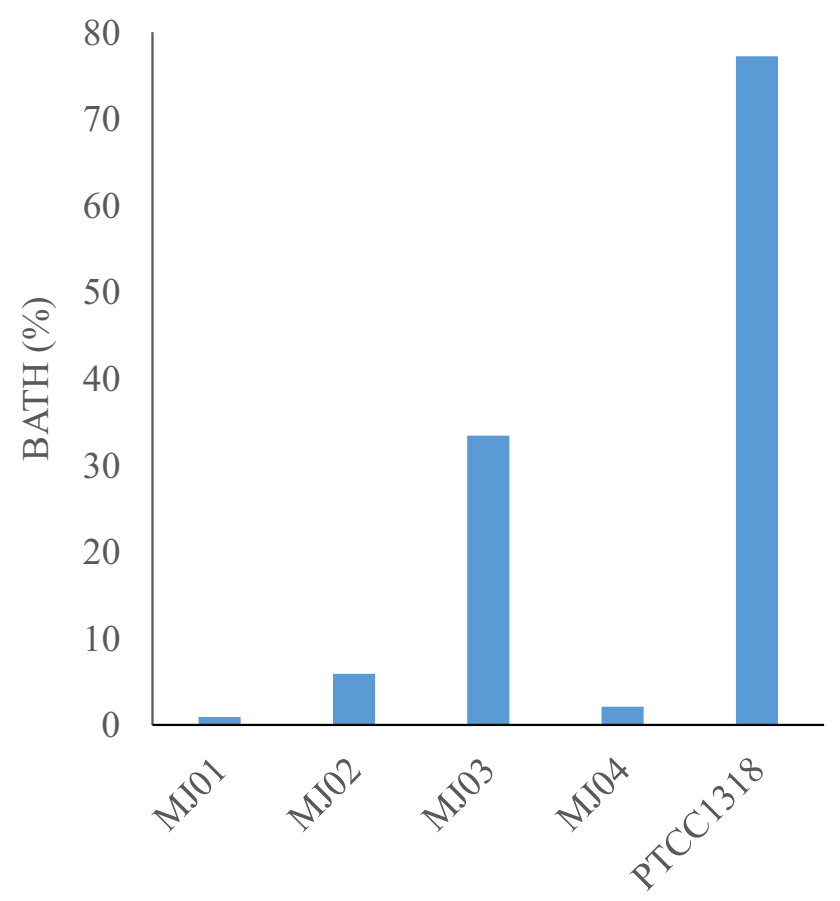

Fig. 2 Bacterial adhesion to hydrocarbon (BATH) for microorganisms used in this work; MJ03 and PTCC 1318 have a significant hydrophobicity, whereas the hydrophobicity of the remaining three strains is negligible

\section{Control solutions}

Table 1, considering the uncertainty in contact angle measurements, shows that at room temperature seawater and distilled water cause a WRP between 0.04 and 0.19 . Therefore, in the following sections when we discuss the effect of biosurfactants and/or microorganisms, we ignore any WRP in this range as it could be achieved without treatment by biosurfactants and/or microorganisms. In the case of seawater, our results are in agreement with (Strand et al. 2008). They showed that seawater cannot influence the wettability of chalk surfaces significantly in temperatures below $100{ }^{\circ} \mathrm{C}$.

\section{Biosurfactant solutions}

Table 2 shows the effect of surfactin and rhamnolipid on the wettability of oil-wet calcite and dolomite surfaces. In zero-salinity condition, surfactin changed the wettability of both calcite and dolomite surfaces to water-wet, while rhamnolipid changed the wettability of the carbonate surfaces to a neutral-wet state. In the salinity of seawater, surfactin was unable to significantly change the wettability of calcite and dolomite rock slices, whereas rhamnolipid altered the wettability to water-wet.

The different effect of surfactin on the wettability compared to that of rhamnolipid can be due to their different hydrophilic-hydrophobic balance (HLB). HLB of surfactin and rhamnolipid has been reported to be 21.27 and 9.5, respectively (Burch et al. 2010; Dehghan-Noudeh et al. 2005). Standnes and Austad (2000) showed that anionic surfactants change the wettability of oil-wet carbonate rocks toward neutral-wet states. They suggested this to be due the formation of a monolayer due to hydrophobic-hydrophobic interactions between hydrophobic heads of the surfactant and carbon components attached on the carbonate surface. In our results, wettability alteration for both biosurfactants, for both calcite and dolomite surfaces, can be explained by the theory of monolayer formation. However, as surfactin bears a bigger hydrophil head, it changes the wettability more. This is shown schematically in Fig. 3a and b.

In seawater, surfactin is unable to change the wettability of oil-wet carbonate surfaces, while dolomite alters wettability completely to a water-wet state. Inability of surfactin in seawater can be due to hydrophilic-hydrophilic interactions between the negatively charged head of surfactin and cations present in the seawater (Fig. 3c). In the case of dolomite, as wettability alteration is more than the distilled water case, it seems that monolayer formation is not the mechanism, and separation of carbon components from the carbonate surfaces has occurred. Note that if monolayer formation was the mechanism, we expected the wettability to be similar with the distilled water case and to be neutral-wet. A schematic presentation of the separation is explained in Fig. 3d. We 
A
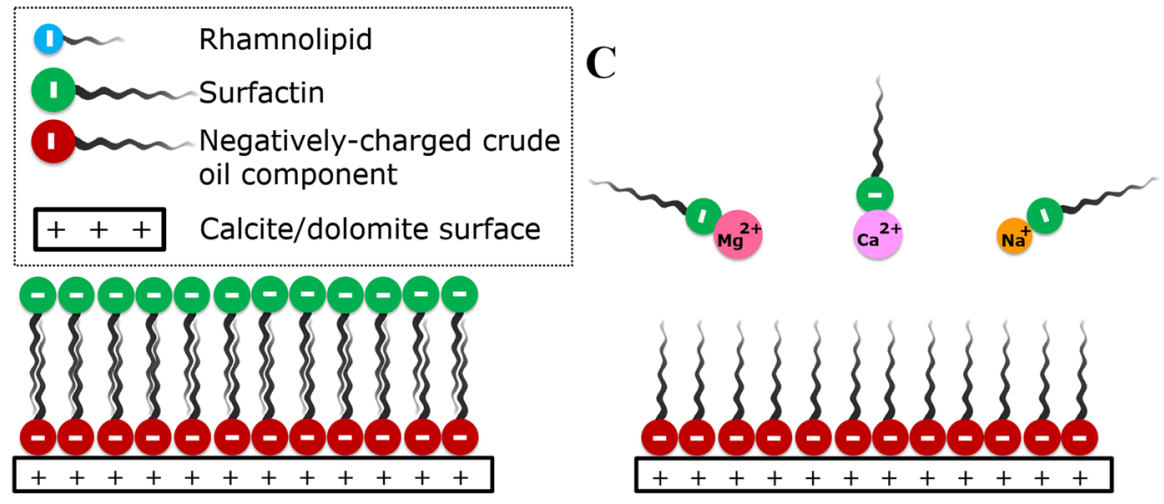

B

D

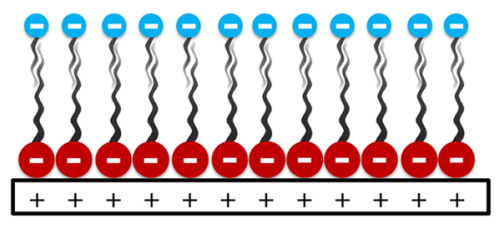

Fig. 3 Surfactin and rhamnolipid can change the wettability of carbonate surfaces depending on salinity. In zero salinity, a surfactin and b rhamnolipid change the wettability to water-wet and neutral-wet states, respectively. This difference seems to be due to different HLBs of these surfactants. In the salinity of the seawater, c electrostatic interaction between the polar head of surfactin and cations presents in the seawater inhibits wettability alteration. $\mathbf{d}$ In the case of rham-

suggest that cations present in the seawater neutralize the negatively charged head of rhamnolipid (by forming cation-biosurfactant complexes). On the other hand, divalent cations present in the seawater help to loosen the interactions between the carbonate surface and the carboxyl group. In this condition, hydrophobic-hydrophobic interactions between rhamnolipid and the carbon component can separate the carbon component from the carbonate surface and changes the wettability to the original water-wet wettability.

\section{Inactive biomass effect}

To study the effect of inactive biomasses, we tested the effect of MJ01 (gram positive) and PTCC 1318 (gram negative) strains. Table 1 shows the results for these tests. It is clear that for none of calcite and dolomite surfaces MJ01 and PTCC 1318 cells are not able to change the wettability significantly. Carbonate surfaces are well known to be positively charged, so they become oil-wet due to adhesion of negatively charged polar components of the petroleum. Inactive microorganisms can be regarded as particles with

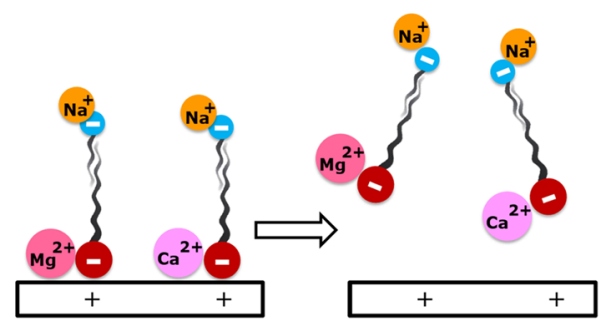

nolipid, divalent cations reduce the polar interactions between the carbonate surface and the carboxyl group. On the other hand, formation of cation-rhamnolipid complexes reduces the electrostatic repulsion between the negatively charged head of rhamnolipid and the carboxyl group. At this condition, hydrophobic-hydrophobic interactions between rhamnolipid and the attached crude oil cause detachment and wettability reversal

a negative charge (Dickson and Koohmaraie 1989). As oilwet calcite and dolomite surfaces are covered by negatively charged components, there is a repulsion force that inhibits microorganisms to adhere to the surface and change the wettability.

\section{Active biomass effect}

We examined 5 different bacteria to investigate how bacteria biologic activity influences the wettability of oil-wet calcite and dolomite surfaces. Table 3 shows that MJ01, MJ02 and MJ04 do not change the wettability significantly, whereas strains MJ03 and PTCC 1318 cause a complete wettability alteration for the case of calcite surfaces and a partial wettability alteration for the case of dolomite surfaces.

We suggest the difference between wettability alteration for MJ03 and PTCC 1318 compared to that of MJ01, MJ02 and MJ04 is due to the different hydrophobicity of these strains. This is schematically shown in Fig. 4. Considering the negative charge of bacteria cells and negative charge of calcite and dolomite oil-wet surfaces, electrostatic forces 
Table 3 Contact angle measurements for calcite and dolomite rock slices before aging, after aging and after treatment by active and inactive bacteria

\begin{tabular}{llllllc}
\hline Status & Strain & Mineral type & \multicolumn{2}{l}{ Contact angle $\left({ }^{\circ}\right)$} & \multirow{2}{*}{$\begin{array}{l}\text { Wettability } \\
\text { alteration }\end{array}$} \\
\cline { 4 - 6 } & & & Initial & Aged & Final & \\
\hline Inactive & \multirow{2}{*}{ MJ01 } & Calcite & $32.4 \pm 0.9$ & $163.8 \pm 2.3$ & $151.2 \pm 2.7$ & $10 \pm 4$ \\
& & Dolomite & $37.8 \pm 1.4$ & $157.7 \pm 3.7$ & $153.7 \pm 2.0$ & $3 \pm 4$ \\
& \multirow{2}{*}{ PTCC 1318 } & Calcite & $29.7 \pm 3.6$ & $150.8 \pm 3.6$ & $137.5 \pm 1.0$ & $11 \pm 4$ \\
& & Dolomite & $34.9 \pm 1.6$ & $169.2 \pm 1.3$ & $150.3 \pm 3.6$ & $14 \pm 4$ \\
Active & \multirow{2}{*}{ MJ01 } & Calcite & $32.4 \pm 3.2$ & $170.4 \pm 0.9$ & $144.6 \pm 0.7$ & $18 \pm 2$ \\
& \multirow{3}{*}{ MJ02 } & Dolomite & $32.5 \pm 2.5$ & $160.2 \pm 1.2$ & $148.2 \pm 4.1$ & $9 \pm 4$ \\
& & Calcite & $34.8 \pm 4.3$ & $150.9 \pm 2.7$ & $132.7 \pm 4.1$ & $16 \pm 7$ \\
& \multirow{2}{*}{ MJ03 } & Dolomite & $44.4 \pm 1.4$ & $162.5 \pm 2.0$ & $147.0 \pm 3.8$ & $13 \pm 5$ \\
& & Calcite & $39.0 \pm 2.0$ & $155.2 \pm 5.3$ & $43.7 \pm 2.7$ & $97 \pm 13$ \\
& \multirow{2}{*}{ MJ04 } & Dolomite & $31.4 \pm 1.4$ & $166.6 \pm 1.1$ & $85.2 \pm 8.1$ & $60 \pm 8$ \\
& Calcite & $30.2 \pm 4.2$ & $166.0 \pm 4.1$ & $156.9 \pm 1.5$ & $7 \pm 4$ \\
& \multirow{2}{*}{ PTCC 1318 } & Dolomite & $34.1 \pm 2.9$ & $159.7 \pm 2.4$ & $145.5 \pm 4$ & $12 \pm 6$ \\
& & Calcite & $36.6 \pm 3.3$ & $165.8 \pm 3.1$ & $42.8 \pm 4.7$ & $96 \pm 10$ \\
& & Dolomite & $28.2 \pm 2.3$ & $165.7 \pm 3.9$ & $90.9 \pm 4.5$ & $55 \pm 8$ \\
\hline
\end{tabular}
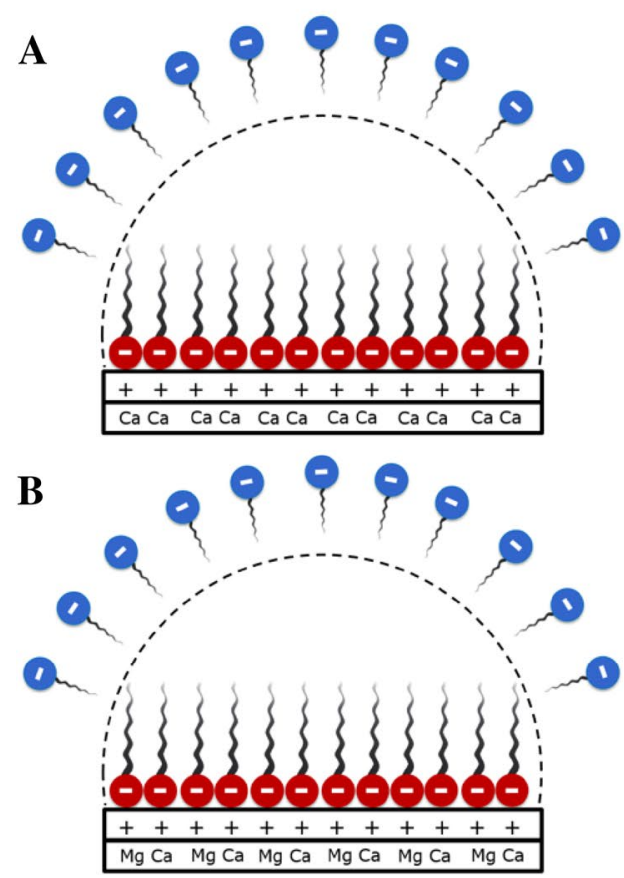

C

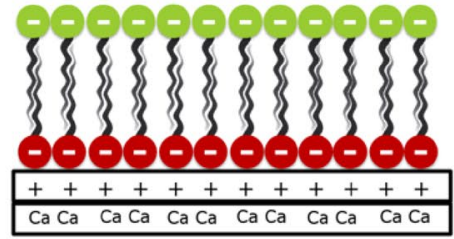

D

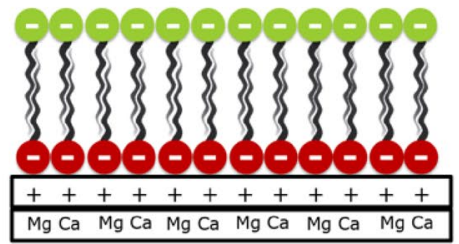

$\mathbf{E}$

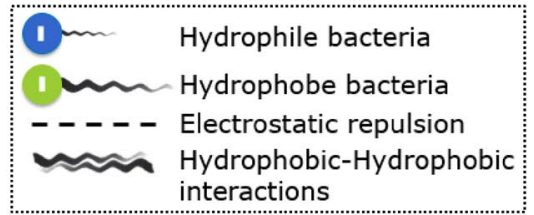

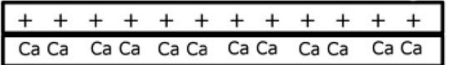

$\mathbf{F}$

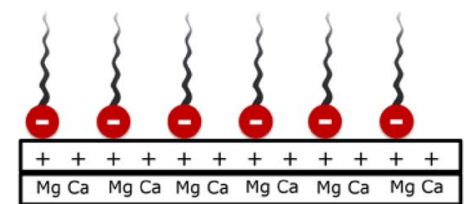

Fig. 4 Different bacteria cells effect on the wettability of oil-wet calcite and dolomite surfaces; electrostatic repulsion between negative charged bacteria and the oil-wet a calcite and $\mathbf{b}$ dolomite surfaces does not allow bacteria to reach the organic matter. In the case of hydrophobic strains, hydrophobic-hydrophobic interactions help bacteria cells to pass the steric hindrance and get access to carbon

are always repulsive between bacteria cells and oil-wet carbonate surfaces. Based on BATH test results, strains MJ01, MJ02 and MJ04 are not hydrophobe, whereas strains MJ03 and PTCC 1318 are slightly hydrophobe and hydrophobe, respectively. Therefore, hydrophobic-hydrophobic interactions (van der Waals forces) between bacteria cells of components on the oil-wet $\mathbf{c}$ calcite and $\mathbf{d}$ dolomite surfaces. Hydrophobic bacteria can loose calcium-carboxylic group bond, whereas they cannot influence magnesium-carboxylic bond; therefore, e calcite surface wettability changes to the original water-wet state, while $\mathbf{f}$ dolomite surface achieves a neutral wettability

MJ03 and PTCC 1318 make them able to get closer to organic components on the calcite and dolomite surfaces (Fig. 4c, d). The absence of these hydrophobic-hydrophobic interactions for hydrophil strains makes them unable to reach organic matter and alter wettability (Fig. 4a, b). 
Considering disability of PTCC 1318 inactive cells to change the wettability, these changes are proved to be due to the biologic activity of bacteria. Figure 5 illustrates an original calcite slice (Fig. 5a) and how its appearance changes throughout the aging process and treatment with active MJ03 strain cells (the same observation was done for PTCC 1318). After aging, the rock slice surface is covered by negatively charged organic components, so the rock slice color changes to black and wettability preference changes to an oil-wet state (Fig. 5b). Active MJ03 strain cells detach most of these organic components, regaining the milky color and wettability preference of the original rock slice (Figs. 4e, 5c).

For dolomite surfaces, treatment by MJ03 and PTCC 1318 leads to a neutral-wet state. The differences between the wettability change for calcite compared to that of dolomite seems to arise from the different interactions of the available reactive sites of the mineral surface with the negatively charged carboxylic group $\left(-\mathrm{COO}^{-}\right)$. At the calcite surface, there are two different surface sites: calcium and carbonates, respectively $\left(>\mathrm{Ca}->\mathrm{CO}_{3}=4.95\right.$ sites/ $\mathrm{nm}^{2}$ ). Besides previously mentioned sites, the dolomite surface contains a third type $\left(>\left(>\mathrm{Ca}=>\mathrm{Mg}=2.6\right.\right.$ sites $/ \mathrm{nm}^{2}$ $->\mathrm{CO}_{3}=5.3$ sites $\left./ \mathrm{nm}^{2}\right)$. Moreover, in a recent publication (Takeya et al. 2019) through electrokinetic measurements it was shown that the interaction of magnesium with the oil polar components (i.e., $-\mathrm{COO}^{-}$) is stronger than the interaction of these latter with calcium. Thus, PTCC 1318 and MJ03 strain cells are able to detach the organic matter from the calcium sites shifting the wettability to water-wet (Fig. 2E), whereas they cannot release the carboxylic acids from the magnesium sites, leaving them oil-wet. As a half of the available sites are calcium and another half are magnesium, a half of the surface sites change to water-wet, while another half remain oil-wet. This leads to a neutral-wet state (Fig. 4f).

\section{Biosurfactants or active biomass, which one should be the MEOR strategy?}

In order to determine an efficient MEOR strategy which utilizes wettability alteration to recover more oil, two points should be considered:

- The salinity of the displacing fluid.

- The rock type.

First, we compare the two examined biosurfactants, and then, we compare using a biosurfactant and active biomass. Based on our results, regardless of the rock type, if fresh water is going to be used as the displacing fluid, surfactin can be more efficient than rhamnolipid since it can cause a complete wettability reversal. However, in practice, seawater or produced water is used as the injecting fluid [reference]. Hence, based on our results, rhamnolipid should be used since surfactin failed to change the wettability in the seawater salinity.

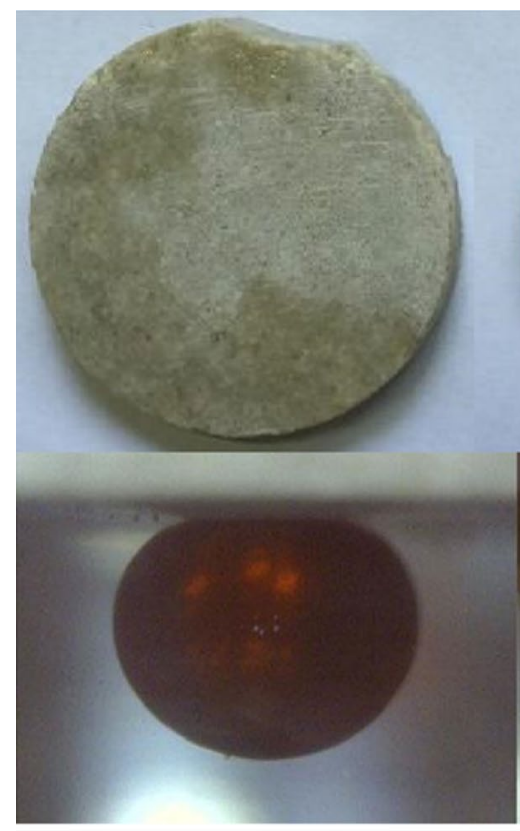

A

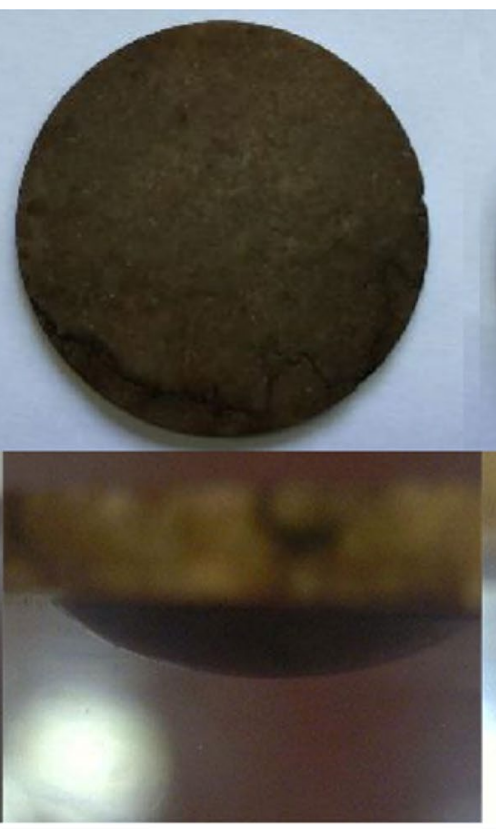

B

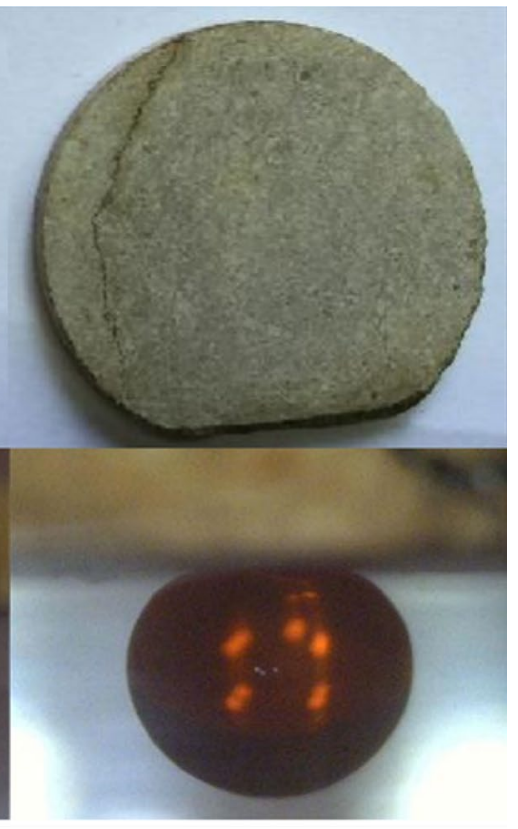

C

Fig. 5 Effect of MJ03 strain cells on a calcite slice; $\mathbf{a}$ untreated surface, $\mathbf{b}$ after aging and $\mathbf{c}$ after treatment by active MJ02 and MJ04 strains 
In the case that the rock type is calcite, rhamnolipid and hydrophobe active biomasses lead to the same wettability alteration; that is, both can lead to the same amount of recovered oil. However, in order to use rhamnolipid, it has to be produced and purified ex situ, while an active biomass can exist in situ and be stimulated via injecting appropriate nutrients. Therefore, in the case that calcite is the major rock type of a carbonate reservoir, utilization of active biomass seems more likely to be economic.

In the case that the rock type is dolomite, utilization of active biomass can cause only a neutral wettability. Even though a neutral wettability state can cause the highest ultimate oil recovery, it has a lower economic oil recovery compared to that of a water-wet state (Anderson 1987). That is, if the rock type is dolomite, while using active biomass is less costly, using rhamnolipid can recover more oil at the breakthrough time. Therefore, more analyses are required to determine the efficient MEOR strategy for a dolomitic carbonate reservoir.

\section{Implications for MEOR, reservoir souring treatment plans and smart water injection}

Conventional MEOR strategies mainly focus on either the role of a bioproduct (that can reduce IFT (Chandankere et al. 2014; Fernandes et al. 2016; Hosseininoosheri et al. 2016; Pereira et al. 2013), change wettability (Najafi-Marghmaleki et al. 2018) and enhance the mobility ratio (Wang et al. 2018) and etc.), or the role of a microorganism to biodegrade oil (Cai et al. 2015; Vilcáez et al. 2018) or reduce its viscosity (Arora et al. 2014). Therefore, in MEOR screening procedures usually most of the indigenous microorganisms are eliminated as they are considered to be incapable of increasing oil recovery (Datta et al. 2018). In fractured carbonate reservoirs, the water flooding is not effective enough since capillary forces do not contribute in oil recovery. To improve water flooding efficiency and get capillary forces to contribute in oil recovery, wettability alteration toward more water-wet states is essential. Therefore, past MEOR research works in this area have mainly focused on how biosurfactant-producing bacteria can change the wettability. For example, Hajibagheri et al. $(2017,2018)$ showed that activity of Enterobacter cloacae can change the wettability. However, they did not make it clear if the biosurfactant is responsible for the wettability alteration or biomass itself. Our results show that bacteria cells and biosurfactants individually can change the wettability. Generally, it is believed that spontaneous imbibition is weakened by reducing IFT Salehi et al. (2008). In this regard, in MEOR plans targeting oil-wet fractured carbonate reservoirs, we suggest to use hydrophobe microorganisms with a low ability to produce biosurfactants, as they change the wettability without weakening capillary forces. We also suggest, in the case that a biosurfactant is to be used, the salinity effect to be studied as different biosurfactants have different behaviors in different salinities.

Reservoir souring is a process in which sulfate reducing bacteria (SRB) reduce sulfate that is present in the injecting seawater and produce $\mathrm{H}_{2} \mathrm{~S}$ (Veshareh and Nick 2019; Veshareh and Nick 2018a, b). Vigneron et al. (2017) for a biologically soured reservoir showed that the reservoir harbors a high variety of sulfate reducers. Since $\mathrm{H}_{2} \mathrm{~S}$ is a toxic and corrosive component, oil operators seek to inhibit this process through different mitigation strategies. Biologic mitigation strategies such as nitrate (Agrawal et al. 2012) and perchlorate treatment (Cheng et al. 2016) try to stimulate some microorganisms against SRB, while non-biologic strategies such as molybdate injection (Newport and Nedwell 1988) try to inhibit any microbial growth in the reservoir. Considering our results, we speculate that reservoir souring process, besides its side effects, has an effect on increasing oil recovery. Biologic treatment strategies substitute the growth of microorganisms such as nitrate-reducing bacteria with the growth of SRB; therefore, by biologic treatment of souring, microbial wettability alteration mechanisms are sustained, whereas by non-biologic treatment we remove souring problem alongside recovery mechanisms.

There are different research works reporting the effect of sulfate ion in increasing oil recovery in smart water injection processes (Austad et al. 2011; Strand et al. 2006; Zhang et al. 2006). Different mechanisms in these works are believed to be the reason for oil recovery. We do not judge the presence of reported mechanisms; however, we speculate that microbial activities are one of the mechanisms of smart water injection, as microorganisms, having hydrophobic characteristics, can utilize sulfate and lead to some extent of oil recovery. Therefore, we feel it is worthy to further study the biologic processes effect on smart water injection tests and oil recovery, especially for imbibition tests where a long period of tests allows significant microbial growth.

\section{Conclusion}

We studied the effect of five different microorganisms cells with different hydrophobicities and two different biosurfactants with different hydrophil-lipophil balances on the wettability of oil-wet calcite and dolomite surfaces. Our results showed that wettability alteration in MEOR processes is not restricted to the presence of biosurfactant. Therefore, our results suggest biologic process effect on the wettability as an ignored part of MEOR, smart water injection and reservoir souring studies. Perhaps considering biologic process effect on the wettability, researchers can design smart water injection and reservoir souring mitigation plans such 
that it maximizes the wettability alteration and oil recovery subsequently.

Open Access This article is distributed under the terms of the Creative Commons Attribution 4.0 International License (http://creativeco mmons.org/licenses/by/4.0/), which permits unrestricted use, distribution, and reproduction in any medium, provided you give appropriate credit to the original author(s) and the source, provide a link to the Creative Commons license, and indicate if changes were made.

\section{References}

Agrawal A, Park HS, Nathoo S, Gieg LM, Jack TR, Miner K, Ertmoed R, Benko A, Voordouw G (2012) Toluene depletion in produced oil contributes to souring control in a field subjected to nitrate injection. Environ Sci Technol 46(2):1285-1292

Al-Bahry S, Al-Wahaibi Y, Elshafie A, Al-Bemani A, Joshi S, AlMakhmari H, Al-Sulaimani H (2013) Biosurfactant production by Bacillus subtilis B20 using date molasses and its possible application in enhanced oil recovery. Int Biodeterior Biodegrad 81:141-146

Anderson WG (1987) Wettability literature survey-part 6: the effects of wettability on waterflooding. J Pet Technol 39(12):1605-1622

Arora P, Ranade DR, Dhakephalkar PK (2014) Development of a microbial process for the recovery of petroleum oil from depleted reservoirs at 91-96 C. Bioresour Technol 165:274-278

Atlas RM (2005) Handbook of media for environmental microbiology. CRC Press, Boca Raton

Austad T (2013) Water-based EOR in carbonates and sandstones: new chemical understanding of the EOR potential using "smart water". In: Sheng JJ (ed) Enhanced oil recovery field case studies. Elsevier, Amsterdam, pp 301-335

Austad T, Matre B, Milter J, Saevareid A, Øyno L (1998) Chemical flooding of oil reservoirs 8. Spontaneous oil expulsion from oil-and water-wet low permeable chalk material by imbibition of aqueous surfactant solutions. Colloids Surf A Physicochem Eng Asp 137(1-3):117-129

Austad T, Shariatpanahi S, Strand S, Black C, Webb K (2011) Conditions for a low-salinity enhanced oil recovery (EOR) effect in carbonate oil reservoirs. Energy Fuels 26(1):569-575

Burch AY, Shimada BK, Browne PJ, Lindow SE (2010) Novel highthroughput detection method to assess bacterial surfactant production. Appl Environ Microbiol 76(16):5363-5372

Cai M, Jiménez N, Krüger M, Guo H, Jun Y, Straaten N, Richnow HH (2015) Potential for aerobic and methanogenic oil biodegradation in a water flooded oil field (Dagang oil field). Fuel 141:143-153

Chandankere R, Yao J, Cai M, Masakorala K, Jain AK, Choi MM (2014) Properties and characterization of biosurfactant in crude oil biodegradation by bacterium Bacillus methylotrophicus USTBa. Fuel 122:140-148

Cheng Y, Hubbard CG, Li L, Bouskill N, Molins S, Zheng L, Sonnenthal E, Conrad ME, Engelbrektson A, Coates JD (2016) Reactive transport model of sulfur cycling as impacted by perchlorate and nitrate treatments. Environ Sci Technol 50(13):7010-7018

Darvishi P, Ayatollahi S, Mowla D, Niazi A (2011) Biosurfactant production under extreme environmental conditions by an efficient microbial consortium, ERCPPI-2. Colloids Surf B 84(2):292-300

Datta P, Tiwari P, Pandey LM (2018) Isolation and characterization of biosurfactant producing and oil degrading Bacillus subtilis MG495086 from formation water of Assam oil reservoir and its suitability for enhanced oil recovery. Bioresour Technol 270:439-448
Dehghan-Noudeh G, Housaindokht M, Bazzaz BSF (2005) Isolation, characterization, and investigation of surface and hemolytic activities of a lipopeptide biosurfactant produced by Bacillus subtilis ATCC 6633. J Microbiol 43(3):272-276

Dickson JS, Koohmaraie M (1989) Cell surface charge characteristics and their relationship to bacterial attachment to meat surfaces. Appl Environ Microbiol 55(4):832-836

Dorobantu LS, Yeung AK, Foght JM, Gray MR (2004) Stabilization of oil-water emulsions by hydrophobic bacteria. Appl Environ Microbiol 70(10):6333-6336

Fernandes P, Rodrigues E, Paiva F, Ayupe B, McInerney M, Tótola M (2016) Biosurfactant, solvents and polymer production by Bacillus subtilis RI4914 and their application for enhanced oil recovery. Fuel 180:551-557

Hajibagheri F, Lashkarbolooki M, Ayatollahi S, Hashemi A (2017) The synergic effects of anionic and cationic chemical surfactants, and bacterial solution on wettability alteration of carbonate rock: an experimental investigation. Colloids Surf A Physicochem Eng Aspects 513:422-429

Hajibagheri F, Hashemi A, Lashkarbolooki M, Ayatollahi S (2018) Investigating the synergic effects of chemical surfactant (SDBS) and biosurfactant produced by bacterium (Enterobacter cloacae) on IFT reduction and wettability alteration during MEOR process. J Mol Liq 256:277-285

Hosseininoosheri P, Lashgari HR, Sepehrnoori K (2016) A novel method to model and characterize in situ bio-surfactant production in microbial enhanced oil recovery. Fuel 183:501-511

Mahani H, Keya AL, Berg S, Bartels W-B, Nasralla R, Rossen WR (2015) Insights into the mechanism of wettability alteration by low-salinity flooding (LSF) in carbonates. Energy Fuels 29(3):1352-1367

Najafi-Marghmaleki A, Kord S, Hashemi A, Motamedi H (2018) Experimental investigation of efficiency of MEOR process in a carbonate oil reservoir using Alcaligenes faecalis: impact of interfacial tension reduction and wettability alteration mechanisms. Fuel 232:27-35

Newport P, Nedwell D (1988) The mechanisms of inhibition of Desulfovibrio and Desulfotomaculum species by selenate and molybdate. J Appl Bacteriol 65(5):419-423

Pereira JF, Gudiña EJ, Costa R, Vitorino R, Teixeira JA, Coutinho JA, Rodrigues LR (2013) Optimization and characterization of biosurfactant production by Bacillus subtilis isolates towards microbial enhanced oil recovery applications. Fuel 111:259-268

Salehi M, Johnson SJ, Liang J-T (2008) Mechanistic study of wettability alteration using surfactants with applications in naturally fractured reservoirs. Langmuir 24(24):14099-14107

Sarafzadeh P, Niazi A, Oboodi V, Ravanbakhsh M, Hezave AZ, Ayatollahi SS, Raeissi S (2014) Investigating the efficiency of MEOR processes using Enterobacter cloacae and Bacillus stearothermophilus SUCPM\# 14 (biosurfactant-producing strains) in carbonated reservoirs. J Pet Sci Eng 113:46-53

Standnes DC, Austad T (2000) Wettability alteration in chalk: 2. Mechanism for wettability alteration from oil-wet to water-wet using surfactants. J Pet Sci Eng 28(3):123-143

Stetter KO, Huber R (2000) The role of hyperthermophilic prokaryotes in oil fields. In: Microbial biosystems: new frontiers: proceedings of the 8th international symposium on microbial ecology, Atlantic Canada Society for Microbial Ecology, Halifax, Canada, pp 369-375

Strand S, Høgnesen EJ, Austad T (2006) Wettability alteration of carbonates-Effects of potential determining ions $\left(\mathrm{Ca}^{2+}\right.$ and $\left.\mathrm{SO}_{4}{ }^{2-}\right)$ and temperature. Colloids Surf A 275(1-3):1-10

Strand S, Puntervold T, Austad T (2008) Effect of temperature on enhanced oil recovery from mixed-wet chalk cores by spontaneous imbibition and forced displacement using seawater. Energy Fuels 22(5):3222-3225

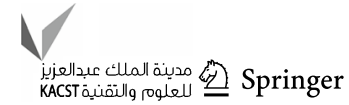


Takeya M, Shimokawara M, Elakneswaran Y, Nawa T, Takahashi S (2019) Predicting the electrokinetic properties of the crude oil/ brine interface for enhanced oil recovery in low salinity water flooding. Fuel 235:822-831

Veshareh MJ, Nick H (2018a) Learnings from reservoir souring treatment by nitrate injection in the Halfdan oil field. In: 80th EAGE conference and exhibition 2018

Veshareh MJ, Nick H (2018b) Nitrate treatment strategy, differences of the reservoir scale and the lab scale. In: First EAGE/IFPEN conference on sulfur risk management in exploration and production

Veshareh MJ, Nick HM (2019) A sulfur and nitrogen cycle informed model to simulate nitrate treatment of reservoir souring. Sci Rep 9(1):7546

Veshareh MJ, Azad EG, Deihimi T, Niazi A, Ayatollahi S (2019) Isolation and screening of Bacillus subtilis MJ01 for MEOR application: biosurfactant characterization, production optimization and wetting effect on carbonate surfaces. J Pet Explor Prod Technol 9(1):233-245. https://doi.org/10.1007/s13202-018-0457-0
Vigneron A, Alsop EB, Lomans BP, Kyrpides NC, Head IM, Tsesmetzis N (2017) Succession in the petroleum reservoir microbiome through an oil field production lifecycle. ISME J 11(9):2141

Vilcáez J, York J, Youssef N, Elshahed M (2018) Stimulation of methanogenic crude oil biodegradation in depleted oil reservoirs. Fuel 232:581-590

Wang T, Yu L, Xiu J, Ma Y, Lin W, Ma T, Wang X, Wang L (2018) A mathematical model for microbial enhanced oil recovery using biopolymer-producing microorganism. Fuel 216:589-595

Zhang P, Tweheyo MT, Austad T (2006) Wettability alteration and improved oil recovery in chalk: the effect of calcium in the presence of sulfate. Energy Fuels 20(5):2056-2062

Publisher's Note Springer Nature remains neutral with regard to jurisdictional claims in published maps and institutional affiliations. 